\title{
Brain Drain and Economic Performance in Small Island Developing States
}

D. de la Croix, F. Docquier and M. Schiff

Discussion Paper 2013-31

\section{Institut de Recherches Économiques et Sociales de l'Université catholique de Louvain}




\title{
Brain Drain and Economic Performance
}

\section{in Small Island Developing States ${ }^{1}$}

\author{
David de la Croix \\ IRES, Université Catholique de Louvain \\ Frédéric Docquier \\ IRES and FNRS, Université Catholique de Louvain \\ Maurice Schiff \\ The World Bank, Development Research Group
}

Forthcoming in: Artal-Tur, A. \& G. Peri \& F. Requena-Silvente (eds), "The Socio-Economic Impact of Migration flows - Effects on Trade, Remittances, Output, and the Labour Market”, Springer (2014).

\begin{abstract}
Brain drain is a major issue for Small Island Developing States (SIDS). Econometric analysis confirms that smallness has a strong positive impact per se on emigration rates. On average, 50 percent of the high-skilled labour force in SIDS has left their country, and the brain drain exceeds 75 percent in a few cases. In this paper, we document this phenomenon and study the bi-directional links between brain drain and development. We show that these interdependencies can be the source of multiple equilibria and that small states are much more likely to be badly coordinated than other developing countries and settle in a bad equilibrium. The reason is that their elasticity of emigration to economic performance is larger. After calibration, we identify an important number of badly coordinated SIDS and quantify the economic costs of coordination failure. These costs may exceed 100 percent of the observed GDP per capita. Badly coordinated small states require appropriate development policies aimed at retaining or repatriating their high-skilled labour force.
\end{abstract}

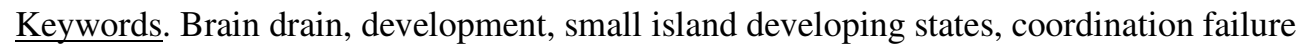

\footnotetext{
${ }^{1}$ This paper combines findings from Beine and Docquier (2008), Beine, Docquier and Schiff (2008) and De la Croix and Docquier (2012). The authors acknowledge financial support from the ARC conventions on "Geographical mobility of factors" and "Sustainability".
} 


\section{Introduction}

An undeniably stylized fact of the last 50 years is that, with a few exceptions, the poorest countries of the world did not catch up with industrialized nations in any meaningful way. Although a considerable amount of research has been devoted to the understanding of growth and development, economists have not yet found how to make poor countries rich. Still, in the quest for growth, increasing human capital has usually been considered an adequate policy. Not surprisingly, improving health and education are among the priorities of the Millennium Summit Declaration.

In this context, it is important to understand and quantify the extent to which globalization of the labour market for highly educated workers affects the capacity of developing countries to accumulate and retain human capital. International migration is a powerful force that shapes the distribution of human capital across the globe. It has long been argued that the brain drain curbs human capital accumulation in poor countries and exacerbates inequality across nations (i.e. makes rich countries richer at the expense of the poor). The brain drain is particularly harmful if concentrated in some strategic occupations (e.g. healthcare, teaching, etc.) and if high-skilled migrants were trained in their country of origin.

For a number of economic reasons (higher degree of specialization, lower moving costs, lack of job opportunities, etc.), the degree of openness of a country is negatively correlated with its population size. Simple partial regressions reveal that the semi-elasticity of import/GDP to population size amounts to $0.072\left(\mathrm{R}^{2}=0.305\right)$, the semi-elasticity of export/GDP to population size amounts to $0.037\left(\mathrm{R}^{2}=0.083\right)$, and the semi-elasticity of emigration rates to population size amounts to $0.053\left(\mathrm{R}^{2}=0.257\right)$. The brain drain is thus highly sensitive to country size (more than exports, less than imports and same as tradel). Our first objective is to document the brain drain of Small Island Developing States (SIDS) and study its determinants. We show that smallness has a strong positive impact on the propensity to emigrate.

Brain drain raises specific concerns for SIDS. Indeed, while exchange rate movements help restoring the balance between imports and exports of goods and services, there is no such mechanism related to the movement of (high-skilled) persons. The new brain drain literature suggests that high-skilled emigration may induce a range of positive feedback effects on sending countries. However these effects are more than likely to be small for SIDS. Diaspora externalities depend on the absolute size of the diaspora and are likely to be negligible for 
small states; no net brain gain can be obtained when the high-skilled emigration rate exceeds 10 or 15 percent (see Beine et al. 2008), which is the case for the vast majority of small countries. Hence, in small developing countries, brain drain sharply reduces the stock of human capital, which is usually considered a fundamental engine of growth. Furthermore, if strong technological externalities are associated with human capital accumulation, highskilled emigration contributes to increasing the wage gaps between the origin and leading countries. In sum, high-skilled emigration is an endogenous phenomenon (a consequence of poverty) and in turn, reinforces poverty in the origin countries.

Our second objective is to understand the interdependencies between high-skill emigration and poverty in developing countries and their economic implications. They can be the source of vicious circles and virtuous cycles linked to strategic complementarities in individual migration decisions. Indeed, when a significant brain drain movement is initiated, it may have damaging effects on the economy and induce other waves of high-skill emigration. On the contrary, when a significant return movement operates, it gives incentives to other waves of emigrants to return home. As documented in the literature, strategic complementarities can be the source of indeterminacy and multiple equilibria. Hence, multiplicity may occur under brain drain and development situations if the intensity of bidirectional links between economic performance and emigration decisions is strong, a situation observed in SIDS. Multiplicity implies that two countries with identical characteristics may end up on different paths, a good one with low poverty and low brain drain, or a bad one with high poverty and high brain drain. Small countries geographically or culturally close to the rich world exhibit stronger responsiveness of migration to the economic environment and are more likely to suffer from coordination failures.

In this paper, we characterize the process of brain drain and human capital accumulation in SIDS, a group of particular interest for development organizations, and we compare it to that of other developing and rich states. There are many possible ways of defining small states. One can use various criteria (population, GDP, territory size in kilometres squared), various thresholds, and various base years. These criteria are strongly correlated and cross-country size differences are well preserved over time. In this paper, we build on the definition of the United Nations (United Nations Conference on Environment and Development in June 1992). The United Nations' Department of Economic and Social Affairs recognizes 52 SIDS. These are broken down into three geographic regions: the Caribbean; the Pacific; and Africa, Indian 
Ocean, Mediterranean and South China Sea. From this set, we first exclude 13 countries classified as high-income countries in the World Bank classification (Aruba, Bahamas, Bahrain, Barbados, French Polynesia, Guam, New Caledonia, Northern Mariana Islands, Puerto Rico, Saint Kitts and Nevis, Trinidad and Tobago, and US Virgin Islands). We then exclude 7 remaining dependent territories administered by larger states (American Samoa, Anguilla, British Virgin Islands, Cook Islands, Montserrat, Netherlands Antilles, and Niue).

We end up with a sample of 32 sovereign SIDS. These are low-lying coastal countries that tend to share similar sustainable development challenges, including small but growing populations, limited resources, remoteness, susceptibility to natural disasters, vulnerability to external shocks, strong dependence on international trade, and fragile environments. Their growth and development is also held back by high communication, energy and transportation costs, irregular international transport volumes, disproportionately expensive public administration and infrastructure due to their small size, and limited opportunity to create economies of scale and diversify their industry. ${ }^{2}$ The average brain drain rate of SIDS exceeds 50 percent and a few countries exhibit rates above 75 percent. This feature is essentially driven by their smallness, not by their development level or geographic position. Then we construct a model endogenizing high-skilled emigration decisions and economic performance in developing countries. We show that multiple equilibria can be observed. Its calibration reveals that small states are much more likely to be badly coordinated because the elasticity of migration to economic performance is larger. Depending on the analytical distribution of migration costs, the number of badly coordinated SIDS varies between 5 and 22 (i.e. between 16 and 69 percent of our sample). For some countries, moving to the good equilibrium can increase wages and GDP per capita by more than 100 percent. Subsidizing temporarily the repatriation of high-skill natives working abroad could lead to major sustainable improvement in these countries.

The remainder of this paper is organized as follows. Sect. 2 studies the determinants of brain drain and shows that small countries exhibit average emigration rates far above those of other developing countries. Sect. 3 presents some stylized facts on emigration patterns and human capital accumulation in the SIDS. Sect. 4 describes a stylized model endogenizing brain drain

\footnotetext{
${ }^{2}$ An open trade regime might, under certain conditions, help partly overcome negative aspects of smallness, namely the limited opportunity of creating economies of scale.
} 
development; the model is calibrated on SIDS and other developing states and characterizes the type of equilibrium observed in each SIDS. Finally, Sect. 5 concludes.

\section{Why do SIDS exhibit larger emigration rates?}

To estimate the determinants of the brain drain and highlight the role of population size, we regress the rate of emigration of skilled workers observed in 1990 and 2000 on various potential determinants. Data on high-skilled emigration rates are taken from Docquier, Lowell and Marfouk (2009), henceforth referred to as DLM. The DLM database documents emigration stocks of all the countries of the world to a set of 30 OECD countries, and the size and structure of the labour force in all countries of the world.

As for emigration, the DLM database comprises a collection of census and register data by country of birth, and education level for OECD countries in 1990 and 2000. DLM enumerates stocks of migrants living in a destination country at the time of the census as opposed to flows that are observed between two points in time. Migration is measured on the basis of country of birth as opposed to citizenship. Only adult migrants aged 25 and above are recorded; this measure therefore excludes both students, who temporarily relocate to complete their education, as well as children who accompany their parents abroad. Three levels are distinguished: those with upper-secondary education, those with more than upper-secondary (some college or university degrees) and those with less (lower-secondary, primary or no schooling). We define the high-skilled as those in the second category, and the low skilled as the sum of the other two categories. As for the labour force, we combine different data sets documenting the size and population structure of the population aged 25 and over (i.e. De La Fuente and Domenech, 2006, Barro and Lee, 2001, and Cohen and Soto, 2007).

Many economic and non-economic factors are likely to explain migrants' decisions. The empirical literature puts forward that emigration rates depend on many push factors at origin, pull factor at destination, distances (cultural and geographic) and immigration policies. We identify the determinants of aggregate emigration rates. As our emigration rates are based on the 1990 and 2000 stocks, they reflect past and recent migration flows. Consequently, we use long-run averages for explanatory time-varying variables when available. We use the following set of controls: 
- The log of GDP per capita and its squared $\left(G D P_{i}, G D P_{i}^{2}\right)$. The neoclassical model of migration predicts that a rise in GDP per capita at origin reduces the incentive to emigrate. However, as shown by Lopez and Schiff (1998), Rotte and Vogler (2000), economic growth in less developed regions might lead to more migration, even if income differentials to the potential destination regions decrease. This can be explained by the importance of financial restrictions on migration, migration networks, and changes in the societal structure of the sending countries as well as the existence of a home preference. Introducing the square of the GDP per capita allows us to capture such effects. We use the World Development Indicators and compute the 1975-2000 average GDP per capita level in PPP value (see http://data.worldbank.org/data-catalog/world-development-indicators).

- Migration costs increase with geographic distance between countries of origin and destination. Although we do not use bilateral data, we introduce the log of the distance in kilometre to the closest OECD country $\left(D I S T_{i}\right)$. Our data come from the CEPII data set which is based on population-weighted bilateral distances between the biggest cities at origin and destination (see Mayer and Zignago, 2011).

- By creating cultural proximities, by providing better information and knowledge on the destination country and thus lowering migration costs, colonial links affect the cultural distance between former colonies and their colonizer(s). In order to capture this effect, we use a dummy variable $\left(C O L_{i}\right)$ which is equal to 1 if the origin country had a colonial relationship with an OECD country. We use the CIA world factbook to build this dummy variable (see https://www.cia.gov/library/publications/the-worldfactbook/).

- Linguistic proximity clearly favours labour exchanges between countries. Skills acquired prior to migration are not equally transferable to all potential host countries. The return to foreign human capital is higher in countries sharing the same language or having the same education system. The literature on migrants' assimilation reveals that migrants get a precious return to their language capacity, especially high-skilled migrants. Chiswick and Miller (1995), among others, found a strong correlation between language skill and immigrants' earnings. Linguistic proximity is expected to favour concentration. We construct a dummy variable $\left(L I N G_{i}\right)$ which is equal to one 
when the origin country shares a common language with countries where economic immigration programs are important (e.g. USA, Canada, Australia and New Zealand). In many instances, the actual impact of being a former colony is closer to the sum of the coefficient of $C O L_{i}$ and $L I N G_{i}$. There is no other reason Ivorians or Congolese speak French than being colonized by the French and Belgians (idem with Indians speaking English or Libyans speaking Italian, etc.).

- We also control for ethnic diversity in origin countries by using religious, linguistic and ethnic fractionalization indicators $\left(F R A C_{i}\right)$. Such fractionalization may impact the psychic costs of migration and affect the desire of people to leave their country. This is especially true in developing countries where fractionalization often gives rise to ethnic or religious conflicts. Our data are taken from Alesina and al. (2003) who computed the probability that two randomly selected individuals belong to different ethnic groups.

- The socio-political environment at origin $\left(P O L_{i}\right)$ also acts as a push factor. To control for political variables, we use two data sets on governance and economic freedom. Data on governance are given in Kaufmann et al. (2003) for 1996, 1998, 2000, 2002 and 2004. From the six available indicators in this data set, we use "political stability and absence of violence" and "government effectiveness". The first indicator measures "perceptions of the likelihood that the government in power will be destabilized or overthrown by possibly unconstitutional and/or violent means, including domestic violence and terrorism". The second indicator measures "quality of public service provision, the quality of the bureaucracy, the competence of civil servants, the independence of the civil service from political pressures, and the credibility of the government's commitment to policies". Both are ranging between -2.5 (bad governance) and 2.5 (good governance). For each country, we average all the available scores. Regarding economic freedom, we use one component of the general index published by the Heritage Foundation, namely the indicator of property rights available from 1995 to 2005. This variable ranges from 1.0 in countries where property rights are well preserved to 4.0 in countries where they are violated. For each country, we average all the available scores. 
- The size of the country of origin is likely to affect the rate of openness. In our regressions, we use the $1975-2000 \log$ of the population size $\left(S I Z E_{i}\right)$. To capture the specific behaviour of small countries, we also use additional dummies for small states $\left(S I D S_{i}\right)$ (population lower than 1.5 million) and subsets of this group. Population data come from the World Development Indicators.

- We use a fixed effect for oil producing countries $\left(O I L_{t}\right)$ and a fixed effect for the year $2000(Y 2000)$.

Our empirical model can be written as:

$$
\begin{aligned}
m_{i t}^{s}= & a_{i}+a_{1} G D P_{i t}+a_{2} G D P_{i t}^{2}+a_{3} D_{I S T_{i}}+a_{4} C O L_{i}+a_{5} L_{I N G_{i}}+a_{6} \text { FRAC }_{i t}+a_{7} P O L_{i t} \\
& +a_{8} \operatorname{SIZE}_{i t}+a_{9} \operatorname{SIDS}_{i}+a_{10} \text { OIL }_{i}+a_{11} Y 2000+\varepsilon_{i t}
\end{aligned}
$$

Results are presented in Tab. 1. We adopt a general-to-specific econometric approach. We first estimate the model using panel data estimation with random effects with all potential determinants included in the regression. In columns (1) and (2), we use two different ways to capture smallness of countries. Column (1) includes specific dummies for countries with less than 1.5 million inhabitants and those with more than 40 million. In column (2), the classification of SIDS is further split between countries with respectively less than $0.5,1$ and 1.5 million inhabitants. In column (3), we estimate a parsimonious specification in which the insignificant variables (such as the large state dummy) are deleted. Finally, as a robustness check of the use of random effects estimates, we estimate the same model using PLS (see column 4).

We find the usual inverted-U relationship between migration and GDP per head of origin countries in PPP values. This result has been found in the previous empirical literature (see Rotte and Vogler, 2000, or Mayda, 2010 among others). An initial increase of the per capita income tends to exert a positive effect on the migration rate since it alleviates liquidity constraints. As the average income increases further, the income difference with the destination countries lowers, which tends to induce less people to migrate. We estimate that the return point is between 2,500 and 3,000 USD. Violation of property rights acts as a push factor. Political stability also seems to act as a push factor. Government effectiveness seems to favour migration, which might seem counterintuitive. One can nevertheless argue that it might be easier to obtain a passport and leave a country whose administrative organization is good. Some caution is nevertheless required when looking at the results of these three 
political variables. The reason is that they are strongly correlated, which raises the issue of collinearity. To account for that, we deleted one or two variables in the parsimonious regressions. The results suggest that these variables do not turn out to be robust determinants of high-skilled emigration. ${ }^{3}$ In contrast, religious fractionalization is a robust determinant in all the specifications. Usual variables such as linguistic proximity, distance and colonial links are also robust. The panel dimension allows us to introduce a specific dummy for the year 2000. The significance of this dummy reflects a general, though moderate increase in the rates of skilled migration between 1990 and 2000.

As for the impact of country size, two general comments are in order. First, as expected, an increase in population size tends to reduce the degree of openness of the country. Second, we find a specific role of smallness beyond the role of population size. The specific dummy variable (capturing whether a given country is small or not) turns out to be significantly positive. A further split of this dummy (column 2) suggests that this result is driven by the very small states, i.e. those with a population below 0.5 million inhabitants. Unreported regressions show that this result is very robust across regression techniques.

Fig. 1 summarizes the relationship between country size (logarithmic scale on the horizontal axis) and the rate of high-skilled emigration (vertical axis). It builds on the estimated coefficients reported in column 4 and average level of other control variables. The slope of the relationship is large and a strong discontinuity is observed for countries where the population size is below 0.5 million. After netting out the effects of traditional push and pull factors, smallness appears as a serious impediment for human capital accumulation per se.

\footnotetext{
${ }^{3}$ The regressions where only one political variable is deleted are not shown but the results hold in those cases as well, i.e., the political variables do not constitute robust determinants of high-skilled migration.
} 
Table 1. Determinants of high-skilled emigration rates

\begin{tabular}{|c|c|c|c|c|}
\hline & (1) & (2) & (3) & (4) \\
\hline Population size in logs & -0.191 & $\begin{array}{c}-0.220 \\
(232) * *\end{array}$ & $\begin{array}{c}-0.208 \\
(2.95) * * *\end{array}$ & $\begin{array}{c}-0.246 \\
(4.56) * * *\end{array}$ \\
\hline \multirow{2}{*}{ Log of GDP per capita } & $\begin{array}{c}(1.94)^{*} \\
4.980\end{array}$ & 5.288 & $\begin{array}{c}(2.95) * * * \\
4.454\end{array}$ & $\begin{array}{l}(4.50) \\
4.352\end{array}$ \\
\hline & $(4.07)^{* * *}$ & $(4.31)^{* * *}$ & $(3.70) * * *$ & $(3.78) * * *$ \\
\hline \multirow[t]{2}{*}{ Log of GDP per capita squared } & -0.311 & -0.329 & -0.272 & -0.274 \\
\hline & $(4.07) * * *$ & $(4.29) * * *$ & $(3.65) * * *$ & $(3.83) * * *$ \\
\hline \multirow[t]{2}{*}{ Oil exporting dummy } & -0.457 & -0.398 & & \\
\hline & (1.31) & (1.13) & & \\
\hline \multirow[t]{2}{*}{ Violation of property rights } & 0.554 & 0.497 & 0.148 & 0.100 \\
\hline & $(2.91)^{* * *}$ & $(2.63)^{* * *}$ & $(0.99)$ & $(0.78)$ \\
\hline \multirow[t]{2}{*}{ Political stability } & -0.366 & -0.366 & & \\
\hline & $(1.69) *$ & $(1.69) *$ & & \\
\hline \multirow[t]{2}{*}{ Government effectiveness } & 0.991 & 0.946 & & \\
\hline & $(3.39) * * *$ & $(3.25)^{* * *}$ & & \\
\hline \multirow[t]{2}{*}{ Religious fractionalization } & 0.910 & 0.982 & 1.070 & 1.184 \\
\hline & $(2.16)^{* *}$ & $(2.31)^{* *}$ & $(2.45)^{* *}$ & $(3.58) * * *$ \\
\hline \multirow{2}{*}{$\begin{array}{l}\text { Linguistic links with selected } \\
\text { countries }\end{array}$} & 0.826 & 0.766 & 0.831 & 0.700 \\
\hline & $(3.69) * * *$ & $(3.44) * * *$ & $(3.71) * * *$ & $(4.18) * * *$ \\
\hline \multirow[t]{2}{*}{ Distance from OECD (in log) } & -0.387 & -0.379 & -0.463 & -0.465 \\
\hline & $(3.66) * * *$ & $(3.58) * * *$ & $(4.37) * * *$ & $(5.59) * * *$ \\
\hline \multirow[t]{2}{*}{ Former colony of OECD country } & 0.935 & 1.007 & 1.013 & 0.763 \\
\hline & $(3.60) * * *$ & $(3.98) * * *$ & $(4.01)^{* * *}$ & $(3.92) * * *$ \\
\hline \multirow[t]{2}{*}{ Year 2000} & 0.217 & 0.225 & 0.196 & 0.077 \\
\hline & $(3.79) * * *$ & $(3.92) * * *$ & $(3.53)^{* * *}$ & $(0.51)^{* *}$ \\
\hline \multirow[t]{2}{*}{ Small states $(<1.5)$} & 1.013 & & & \\
\hline & $(2.50)^{* *}$ & & & \\
\hline \multirow{2}{*}{ Large states $(>40)$} & -0.169 & -0.145 & & \\
\hline & $(0.65)$ & $(0.56)$ & & \\
\hline \multirow[t]{2}{*}{ Small states A (from 0 to .5 ) } & & 1.179 & 1.035 & 1.024 \\
\hline & & $(2.25)^{* *}$ & $(2.06)^{* *}$ & $(2.75)^{* * *}$ \\
\hline \multirow[t]{2}{*}{ Small states B (from .5 to 1.5 ) } & & 0.308 & & \\
\hline & & (1.12) & & \\
\hline \multirow[t]{2}{*}{ Constant } & -18.906 & -19.633 & -15.379 & -13.329 \\
\hline & $(3.77) * * *$ & $(3.87) * * *$ & $(3.13) * * *$ & $(2.90)^{* * *}$ \\
\hline No. of observations & 285 & 285 & 285 & 285 \\
\hline No. of Countries & 153 & 153 & 153 & 153 \\
\hline R-squared & 0.41 & 0.42 & 0.36 & 0.37 \\
\hline
\end{tabular}


Figure 1. Population size and average high-skilled emigration rate

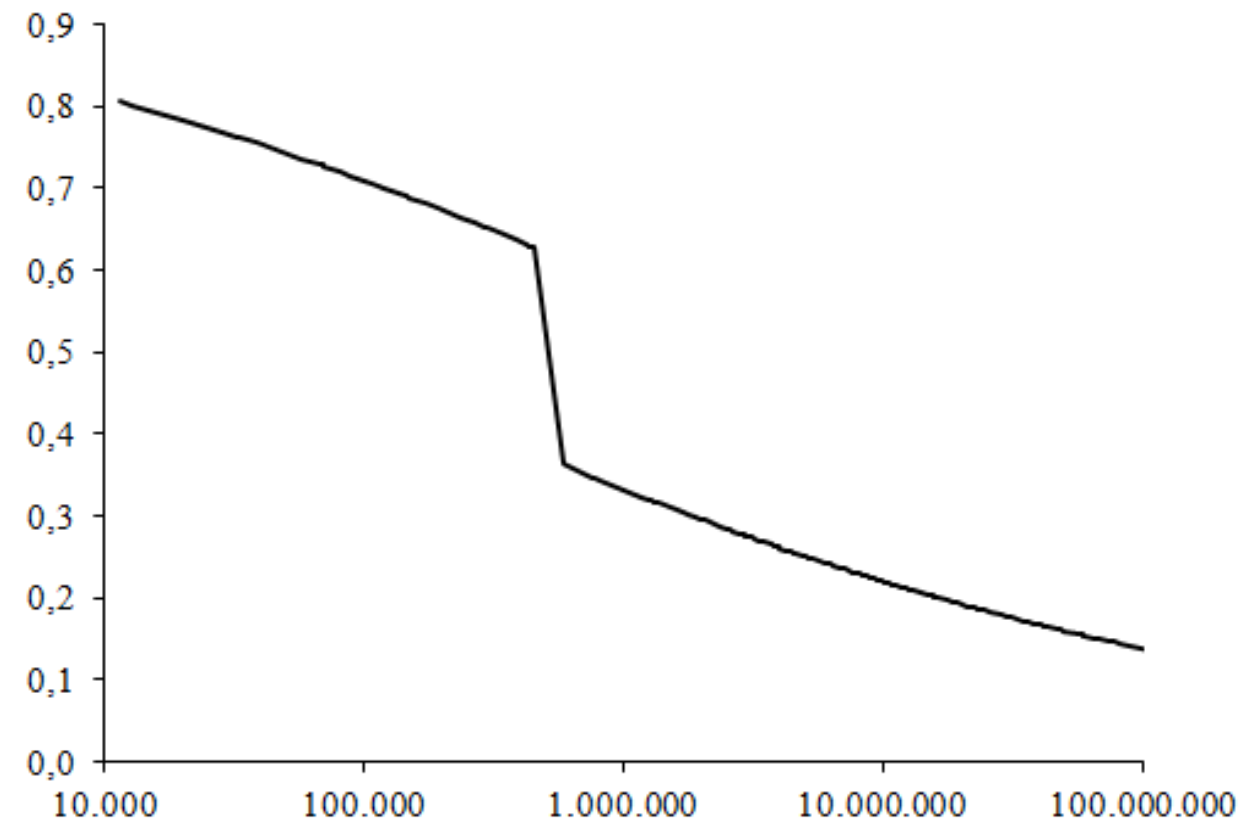

Note. High-skilled emigration rate (as percent of the high-skilled native population) is measured on the vertical axis. Population size is measured on the horizontal axis, with a logarithmic scale.

\section{How big is the brain drain from SIDS?}

To characterize emigration patterns and human capital accumulation of SIDS, we use the DLM database and focus on the 2000 wave. The role of population size on human capital accumulation is important. Tab. 2 provides measures of emigration and human capital for the year 2000. We distinguish the set of 32 SIDS described in Sect. 1, the mean of SIDS, the average of other developing countries, and the average of high-income countries. Columns 1 and 2 give the ratio of high-skilled to low-skilled workers in the native (or natural) labour force and in the resident labour force. The native labour force is proxied by the sum of residents and emigrants to OECD destinations. Columns 3 and 4 give the emigration rates of high-skilled and low-skilled workers, computed as the ratio of emigrants to the native labour force in each education group. Unweighted average levels are reported in the last three rows of the table. 
Table 2. Human capital and emigration in SIDS, year 2000

\begin{tabular}{|c|c|c|c|c|c|}
\hline \multirow[b]{2}{*}{ Country } & \multicolumn{2}{|c|}{ Skill ratio } & \multicolumn{2}{|c|}{ Emigration rates } & \multirow{2}{*}{$\begin{array}{l}\text { Native LF } \\
\text { (x 1,000) }\end{array}$} \\
\hline & $\begin{array}{l}\text { Among } \\
\text { natives }\end{array}$ & $\begin{array}{l}\text { Among } \\
\text { residents }\end{array}$ & $\begin{array}{c}\text { College } \\
\text { graduates }\end{array}$ & $\begin{array}{c}\text { Less } \\
\text { educated }\end{array}$ & \\
\hline Antigua \& Barbuda & 0.334 & 0.135 & 0.685 & 0.221 & 53.6 \\
\hline Belize & 0.228 & 0.098 & 0.655 & 0.197 & 132.8 \\
\hline Cape Verde & 0.081 & 0.064 & 0.440 & 0.293 & 228.4 \\
\hline Comoros & 0.028 & 0.024 & 0.178 & 0.035 & 258.4 \\
\hline Cuba & 0.165 & 0.127 & 0.288 & 0.077 & $8,145.3$ \\
\hline Dominica & 0.307 & 0.169 & 0.639 & 0.346 & 55.1 \\
\hline Dominican Republic & 0.192 & 0.169 & 0.224 & 0.119 & $4,258.6$ \\
\hline East Timor & 0.044 & 0.035 & 0.219 & 0.021 & 274.8 \\
\hline Fiji & 0.179 & 0.076 & 0.628 & 0.130 & 472.0 \\
\hline Grenada & 0.347 & 0.096 & 0.843 & 0.430 & 72.3 \\
\hline Guinea-Bissau & 0.013 & 0.010 & 0.277 & 0.033 & 489.4 \\
\hline Guyana & 0.265 & 0.041 & 0.892 & 0.308 & 620.7 \\
\hline Haiti & 0.061 & 0.013 & 0.799 & 0.075 & $3,351.9$ \\
\hline Jamaica & 0.210 & 0.043 & 0.847 & 0.245 & $1,949.3$ \\
\hline Kiribati & 0.033 & 0.015 & 0.557 & 0.023 & 52.7 \\
\hline Maldives & 0.141 & 0.127 & 0.110 & 0.017 & 106.7 \\
\hline Marshall Islands & 0.126 & 0.077 & 0.428 & 0.063 & 32.4 \\
\hline Mauritius & 0.122 & 0.095 & 0.285 & 0.086 & 747.6 \\
\hline Micronesia Fed. States & 0.113 & 0.076 & 0.357 & 0.047 & 44.6 \\
\hline Nauru & 0.058 & 0.026 & 0.573 & 0.034 & 5.9 \\
\hline Palau & 0.208 & 0.097 & 0.547 & 0.033 & 50.9 \\
\hline Papua New Guinea & 0.037 & 0.031 & 0.158 & 0.005 & $2,092.2$ \\
\hline Saint Lucia & 0.127 & 0.047 & 0.686 & 0.157 & 96.6 \\
\hline St Vincent \& Grenadines & 0.236 & 0.058 & 0.819 & 0.267 & 83.5 \\
\hline Samoa & 0.170 & 0.077 & 0.734 & 0.414 & 133.8 \\
\hline Sao Tome \& Principe & 0.038 & 0.031 & 0.267 & 0.103 & 52.9 \\
\hline Seychelles & 0.217 & 0.161 & 0.400 & 0.189 & 34.9 \\
\hline Solomon Islands & 0.020 & 0.015 & 0.257 & 0.004 & 154.2 \\
\hline Suriname & 0.151 & 0.092 & 0.658 & 0.440 & 395.5 \\
\hline Tonga & 0.187 & 0.076 & 0.756 & 0.399 & 75.9 \\
\hline Tuvalu & 0.043 & 0.020 & 0.575 & 0.115 & 5.5 \\
\hline Vanuatu & 0.136 & 0.077 & 0.475 & 0.073 & 85.3 \\
\hline SIDS (average) & 0.144 & 0.072 & 0.508 & 0.156 & 769.2 \\
\hline Larger developing states (average) & 0.094 & 0.084 & 0.140 & 0.027 & $22,690.9$ \\
\hline High-income countries (average) & 0.303 & 0.282 & 0.130 & 0.057 & $14,466.5$ \\
\hline
\end{tabular}

Source: Docquier, Lowell and Marfouk (2009). 
On average, emigration rates of SIDS are far above those of other developing countries and high-income countries. This is true for low-skilled workers (15.6\%, i.e. about 13 percentage points above the average level of other developing countries) and for college graduates (50.8\%, i.e. about 37 percentage points above the average level of other developing countries). Countries exhibiting the largest brain drain rates are Guyana (89.2\%), Jamaica (84.7\%), Grenada (84.3\%), Saint Vincent and Grenadines (81.9\%), Haiti (79.0\%), Tonga $(75.6 \%)$ and Samoa $(73.4 \%)$.

High-skilled emigration from SIDS affects their capacity to accumulate human capital. The skill ratio computed on the native population (0.144) exceeds the average level of larger developing countries (0.094). Once migration is netted out, the skill ratio of SIDS falls to 0.072 whereas that of other developing countries reaches 0.084 . It is worth noting that, in the absence of migration, some small states would exhibit a skill ratio exceeding the average level of high-income countries (i.e. a level above 0.303): Grenada (0.347), Antigua and Barbuda (0.334), and Dominica (0.307). Other SIDS would be very close from the level observed in rich countries: Guyana (0.265), Saint Vincent and Grenadines (0.236), Belize (0.228), Seychelles (0.217), Jamaica (0.210), Palau (0.208).

\section{Modelling brain drain and development}

To study interdependencies between high-skilled emigration decisions and economic performance, we use a static model with two types of native workers, the highly skilled and the low skilled (i.e. workers with college education and the less educated). Workers decide whether to emigrate or to stay in their home country, and the skill ratio (i.e. the ratio of highskilled to low-skilled workers) among remaining residents determines the level of economic performance of the country. In this section, we first describe the general model and demonstrate that multiple equilibria can be observed. Our model is a static version of the model presented in de la Croix and Docquier (2012). We then conduct a static comparative analysis using a uniform distribution for migration costs. Finally, we calibrate the model and show that small states are more likely to be badly coordinated. The reason is that the average migration cost is lower for workers originating from small states; hence, the elasticity of migration to economic performance is larger. 


\subsection{Theory}

The adult population is divided in two groups: we denote by $N_{h}$ the number of native-born individuals with higher education, and by $N_{l}$ the number of less educated natives. The skill ratio in the native (or natural) population is denoted by $z \equiv N_{h} / N_{l}$, referred to as the native skill ratio. This variable is considered as predetermined and exogenous in our model.

The emigration rates are denoted by $m_{h} \in[0 ; 1]$ for the high-skilled and $m_{l} \in[0 ; 1]$ for the less educated; the latter is assumed to be exogenously determined by immigration restrictions in the leading destination countries. On the contrary, high-skilled emigration rates are endogenous. The size of the resident labour force is determined by $L_{h}=N_{h}\left(1-m_{h}\right)$ and $L_{l}=N_{l}\left(1-m_{l}\right)$. Hence, the skill ratio in the resident labour force $h$ is given by:

$$
h \equiv \frac{L_{h}}{L_{l}}=z \frac{1-m_{h}}{1-m_{l}}
$$

referred to as the resident skill ratio.

For a given level of $z$, Eq. (1) shows how high-skilled emigration $m$ affects the skill structure of the labour force remaining in the country. Inverting (1), we obtain (1') which will be referred to as the skill-setting condition:

(1') $\quad m_{h}=1-\frac{h}{z}\left(1-m_{l}\right) \equiv \phi_{s}(h) \quad$ (Skill-setting curve)

The economy is characterized by a linear production function with perfect substitution between high-skilled and less educated workers, ${ }^{4}$ and an endogenous scale productivity factor, $w$. We can write:

$$
Y=w\left[L_{h}+\omega L_{l}\right]
$$

where $\omega<1$ is the average productivity of less educated workers relative to the highly skilled; with competitive pricing, high-skill workers' income is equal to $w$ whereas low-skill workers earn $\omega w$. The assumption of perfect substitutability of the two types of labour implies that the skill premium is exogenous.

\footnotetext{
${ }^{4}$ Although it is made for mathematical simplicity, this assumption is in line with many empirical studies advocating to use a high elasticity of substitution to match data on the skill premium in developing countries.
} 
We consider a Lucas-type technological externality (see Lucas, 1988) and assume that the scale productivity factor is a concave function of the skill-ratio in the resident labour force. Hence, we have

$$
w=A h^{\alpha},
$$

where $A$ is a constant, $\alpha \in[0 ; 1]$ is a structural elasticity of productivity to the skill ratio (assumed to be lower than one).

Azariadis and Drazen have emphasized the fact that threshold externalities characterize the process of development. Eq. (3) can be seen as a smooth approximation of a step function. This is illustrated on Fig. 2 where the static relationship between the scale productivity factor and the economy-wide skill ratio is represented by a step function with many levels, or its smooth approximation.

Figure 2. Productivity scale and the skill ratio

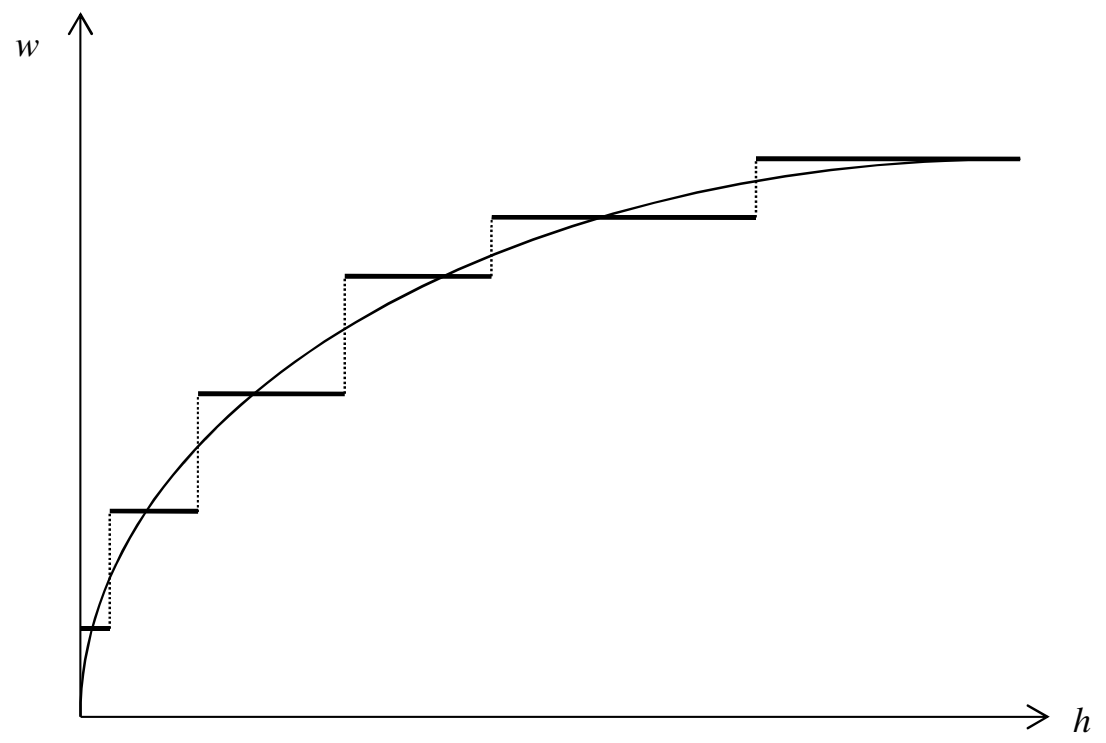

Workers can emigrate to a rich country. On the one hand, we consider the emigration rate of the low-skilled as exogenous, determined by immigration restrictions in the destination countries. This is justified by the fact that low-skilled emigration rates are low in many developing countries: DLM report an average rate of 1.3 percent in 2000. In addition, empirical studies show that low-skilled emigration is less responsive to economic variables 
than high-skilled emigration. On the other hand, high-skilled emigrants decide to stay or to emigrate on the basis of labour market conditions in their home country. Their preferences are represented by an indirect utility function assumed to be logarithmic in income: their utility is simply given by $\ln w_{t}$ if they stay in the home country.

In line with (3), income at destination is denoted by $\bar{w}_{t}=\bar{A} \bar{h}^{\alpha}$, where $\bar{A}$ and $\bar{h}$ are the exogenous levels of the scale productivity and skill ratio in destination countries. Each SIDS is too small to affect $\bar{h}$ in any meaningful way. However migration induces heterogeneous moving costs which must be subtracted from the utility level abroad. We denote the migration cost of and individual by $c$ (individual subscripts are omitted for clarity) and denote by $G(c)$ the cumulative distribution function $(\mathrm{CDF})$ of this variable. Hence, migration is optimal for all high-skilled workers such that $\ln \bar{w}-c>\ln w$. In other words, all college graduates with migration costs below a critical value $c_{0}$ find it optimal to emigrate. The critical value and optimal high-skilled emigration rates are given by

$$
\begin{aligned}
& c_{0}=\ln \frac{\bar{A}}{A}+\alpha \ln \frac{\bar{h}}{h} \\
& m_{h}=G\left[c_{0}\right]=G[X-\alpha \ln h] \equiv \phi_{m}(h) \quad \text { (Migration-Setting curve) }
\end{aligned}
$$

where $X \equiv \ln \bar{A}-\ln A+\alpha \ln \bar{h}$ is a combination of parameters and exogenous country-specific variables. We will refer to Eq. (5) as the Migration-Setting equation.

We impose the following properties for $G(c)$ :

Assumption. The CDF $G(c)$ is non-decreasing in $c\left(G^{\prime} \geq 0\right)$, takes values between 0 and 1 , and is such that $G(0)=0$ and $G(\bar{c})=1$.

The first two conditions are standard properties of CDF's. The last two conditions imply that individual migration costs cannot be negative and are bounded from above: $c \in[0 ; \bar{c}]$. Given this hypothesis, we obtain the following lemma:

Lemma . There exists a threshold level of the resident skill ratio, $\hat{h} \equiv \exp [(X-\underline{c}) / \alpha]$, below which all educated migrants decide to leave the country. 
Proof. The threshold value $\hat{h}$ solves $X-\alpha \ln h=\bar{c}$. Using (5), all countries $h \leq \hat{h}$ are such that the critical level of migration cost $c_{0}$ below which migration is desirable exceeds the upper bound of the distribution, $\bar{c} \cdot Q E D$

Our model can be used to characterize the equilibrium of all countries. Each country $\Omega$ is characterized by its distribution of migration costs, $G(c)$, and a quadruple of country-specific variables $\Omega=\left(z, m_{l}, \bar{c}, A\right)$. Other ingredients $\Lambda \equiv(\omega, \alpha, \bar{A}, \bar{h}$,$) are assumed to be identical$ across countries and considered as structural parameters of the model. Given the parameter set $\Lambda$, an equilibrium for country $\Omega$ is a pair consisting of the skills ratio and the high-skilled emigration rate, $\left(h, m_{h}\right)$, satisfying conditions (1') and (5), i.e. an intersection between the skill-setting and migration-setting curves. Once the pair $\left(h, m_{h}\right)$ is determined, the level of other endogenous variables $(w, Y)$ is also known. The interesting feature of this model is that interactions between the human capital accumulation and emigration decisions may generate multiple equilibria.

Proposition. For a given native skill ratio $z$, if one interior solution exists for $\left(h, m_{h}\right)$, then at least two solutions exists.

Proof. From (1); the skill-setting condition $\phi_{s}(h)$ is a downward-sloping line such that $\phi_{s}(0)=1$ and $\phi_{s}\left(z /\left(1-m_{l}\right)=0\right.$. Because $m_{l}, z \in[0 ; 1], z /\left(1-m_{l}\right)$ is positive and finite (see black line on Fig. 3). From (5), the migration-setting condition is such that $\phi_{m}(h)=1$ for any $h \leq \hat{h}$, and $\lim _{h \rightarrow \infty} \phi_{m}(h)=0$ (see grey curve on Fig. 3). Two possibilities arise: (i) either the migration-setting curve is always above the skill-setting curve and there is no interior solution, or (ii) the migration-setting curve intersects at least twice with the skill-setting curve. $Q E D$.

Two possibilities are represented in Fig. 3. More complex configurations with more than two interior solutions can be obtained for particular CDF's. The left panel on Fig. 3 shows a configuration with the corner solution (A) and two interior solutions (B and C). The bidirectional causal link between emigration and poverty induces both vicious circles and virtuous cycles, due to strategic complementarities in individual emigration decisions. Indeed, when a significant brain drain movement is initiated, it might have adverse effects on the 
economy, begetting yet further waves of high-skill emigration. The converse also holds true, when a mechanism of net return prevails, it provides incentives to further waves of returnees. Equilibria $\mathrm{A}$ and $\mathrm{B}$ can result from coordination failure in high-skilled emigration decisions. Both are Pareto-dominated by equilibrium $\mathrm{C}$. The right panel shows a configuration with a unique corner solution (A).

When multiplicity occurs, it is worth investigating whether each equilibrium is robust to the possibility that some players may make small mistakes (i.e. is it trembling-hand perfect?). Equilibrium $\mathrm{A}$ and $\mathrm{C}$ are trembling-hand perfect because the migration-setting curve in grey is flatter than the skill-setting curve in black. Starting from C, suppose that some agents decide to emigrate more ( $\mathrm{C}$ shifts upwards); given the skill-setting curve, human capital decreases but less than what is sustained by the migration-setting curve. Equilibrium B is not tremblinghand perfect because the migration-setting curve in grey is less flat than the skill-setting curve. However, this only holds true when the migration-setting curve is smooth. If we allow for threshold technological externalities as depicted in Fig. 2, the migration-setting curve becomes a step function with many horizontal segments and each intersection can become trembling-hand perfect. For this reason, we consider equilibrium B as a possible outcome.

Figure 3. The case for multiple temporary $\left(m_{h}, h\right)$ equilibria for $z$ given
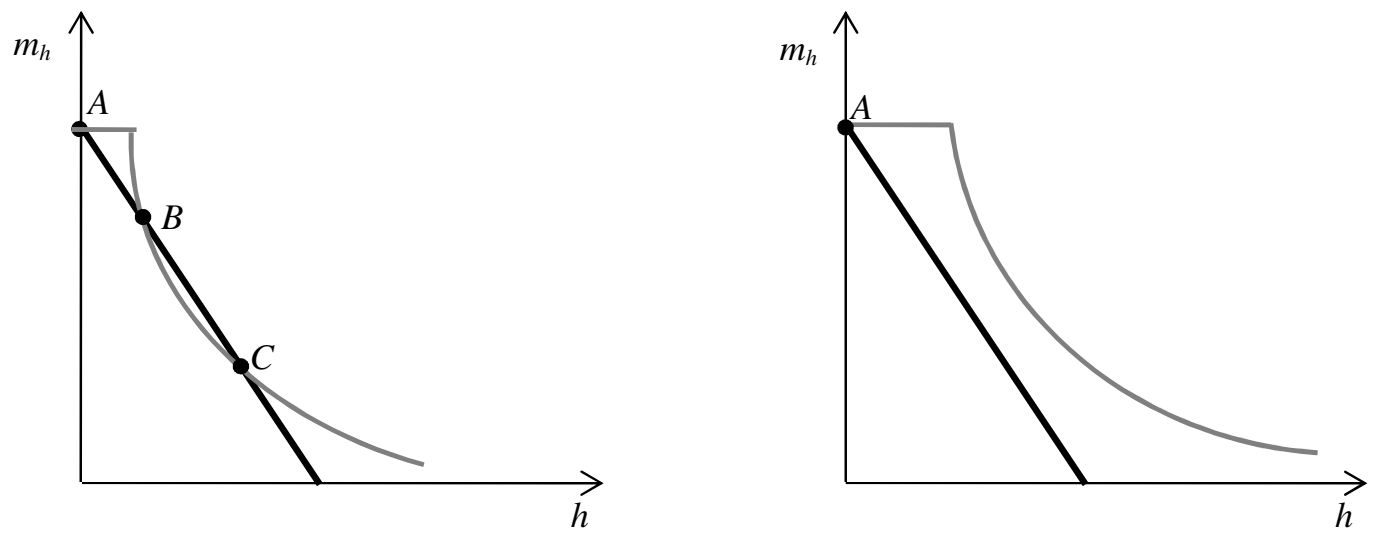


\subsection{Comparative analysis with uniform distribution of migration costs}

How do country characteristics $\Omega=\left(z, m_{l}, A, \bar{c}\right)$ affect the equilibrium pair of brain drain and development? As shown on Tab. 1, each country has a high-skilled emigration rate comprised between 0 and 1 (interior solution). We consider that the left panel of Fig. 3 is the benchmark representation and investigate how a change in parameters modifies interior equilibria $\mathrm{B}$ and C. We denote the resident skill ratio and brain drain rate at equilibria $\mathrm{B}$ and $\mathrm{C}$ by $\left(h_{B}, m_{B}\right)$ and $\left(h_{C}, m_{C}\right)$, respectively.

To address this question, let us assume that the CDF of migration costs is uniform, i.e. $G(c)=c / \bar{c}$. Then the migration setting equation becomes

$$
m_{h}=\operatorname{Min}\left[\frac{X}{\bar{c}}-\frac{\alpha}{\bar{c}} \ln h ; 1\right] \equiv \phi_{m}(h),
$$

which, together $\hat{h} \equiv \exp [(X-\underline{c}) / \alpha]$ and $X \equiv \ln \bar{A}-\ln A+\alpha \ln \bar{h}$, characterizes the shape of the migration-setting equation. The skill setting curve is given by Eq. (1').

First, changes in the native skill ratio, $z$, and changes in the low-skilled emigration rate, $m_{l}$, only modify the skill-setting equation. As $z$ or $m_{l}$ increases, the skill-setting curve pivots to the right. We have $\partial m_{B} / \partial\left(z, m_{l}\right)>0, \quad \partial h_{B} / \partial\left(z, m_{l}\right)<0, \quad \partial m_{C} / \partial\left(z, m_{l}\right)<0 \quad$ and $\partial h_{c} / \partial\left(z, m_{l}\right)>0$. Hence, an increase in the native skill ratio or low-skilled emigration rate worsens the bad equilibrium, improves the good one, and raises the distance between the two equilibria.

Second, a change in the upper bound of the distribution of migration costs, $\bar{c}$, only modifies the migration-setting equation. As $\bar{c}$ increases, $\hat{h}$ decreases (i.e. the migration-setting curve shifts to the left for low levels of human capital) as well as the constant and the slope (in absolute value) of the migration-setting curve. From (6), it is straightforward to show that an increase in $\bar{c}$ shifts the migration shifts downward if $X-\alpha \ln h$ is positive. This situation is likely to be observed in most developing countries because $X$ is usually positive and $\ln h$ is negative. We have $\partial m_{B} / \partial z>0, \partial h_{B} / \partial z<0, \partial m_{C} / \partial z<0$ and $\partial h_{c} / \partial z>0$. As with $z$, an increase in average migration costs deteriorates the bad equilibrium and improves the good one. 
Similarly, a change in total factor productivity, $A$, only modifies the migration-setting equation through the constant $X$. As $A$ increases, $\hat{h}$ and $X$ decreases: the migration-setting curve shifts to the left and downwards. Again, an increase in productivity worsens the bad equilibrium and improves the good one.

Provided that mass brain drain is a relatively recent phenomenon and the low brain drain equilibrium $\mathrm{C}$ is trembling-hand perfect, the likelihood to observe a coordination failure (i.e. countries for which the bad equilibrium B is selected) depends on how people might have deviated from the good equilibrium when adverse historical shocks happened in the recent past. The probability to reach equilibrium B depends, plausibly, on the distance between B and C. As demonstrated in the comparative static analysis, this distance increases with the level of native human capital, low skilled emigration rate, the average level of migration costs, and the scale of the exogenous productivity factor.

\subsection{The case of SIDS}

To illustrate that SIDS are more likely to be badly coordinated, we need to calibrate country-

specific parameters, $\Lambda \equiv(\omega, \alpha, \bar{A}, \bar{h})$, and general parameters, $\Omega=\left(z, m_{l}, A, \bar{c}\right)$, and compare configurations obtained for SIDS and for other developing or high-income countries.

Data on emigration and labour force are obtained from DLM. In particular, data on native and resident skill ratios, $z$ and $h$, and low-skilled emigration rates, $m_{l}$, were reported in Tab. 1. It is worth noting that SIDS exhibit large native skill ratios and low-skilled emigration rates.

As for the relative productivity of low-skilled workers, we rely on Rosenzweig $(2007,2008)$ who estimated an average return to schooling of about 9.5 percent per year in developing countries. Considering that high-skill workers have 10 more years of schooling than the low skilled, we obtain $\omega=0.4$. On average, college graduates are 2.5 more productive than less educated workers.

To calibrate the elasticity of productivity to the skill ratio, $\alpha$, we use data on GDP from the World Bank indicators on the labour force. For each country, we calibrate $w$ as the residual of Eq. (2). Then, regressing $\ln w$ on $\ln h$, we obtain a slope of 0.8 , as illustrated on Fig. 4. We use this elasticity for $\alpha$. 
Once $\alpha$ is determined, the productivity scale $A$ can be calibrated for each country as the residual of Eq. (3) for each country. Results are presented in Tab. 2: on average, SIDS exhibits larger scale productivity factors than other developing countries (+20 percent), but lower levels than in high-income countries (-40 percent). The same exercise is conducted for high-income countries: we use the average scale productivity of high-income countries for $\bar{A}$, and consider a value of 1 for $\bar{h}$. This determines $X$ for each developing country.

Finally, we use Eq. (6) to calibrate $\bar{c}$. We observed high-skilled emigration rates, $m$, and have identified all the components of the right-hand side term, except $\bar{c}$. We thus calibrate $\bar{c}$ without imposing the type of equilibrium (good or bad) observed in the country. In Tab. 3, we observe that average migration costs in SIDS are four times lower than in high-income countries (despite many labour mobility agreements between rich countries) and 7 times lower than in other developing countries. This is a major difference shortening the distance between the good and bad equilibria and increasing the likelihood of coordination failures.

Figure 4. Calibration of the elasticity of productivity to the skill ratio $(\alpha)$

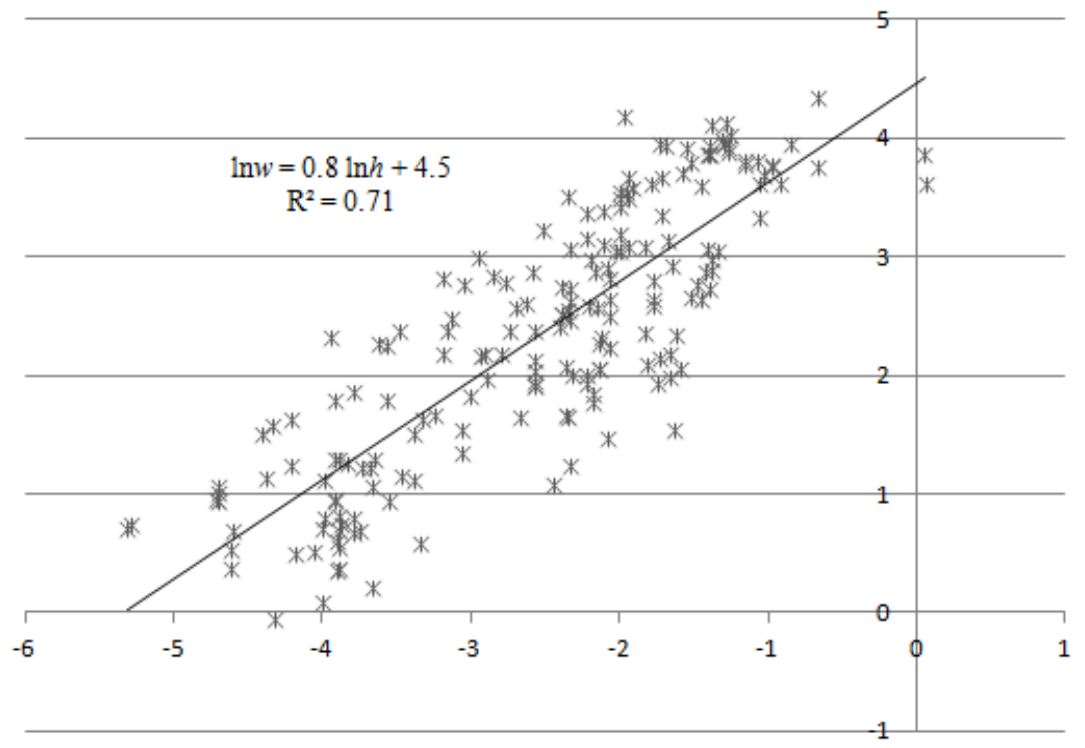

Using the average parameter values for SIDS, other developing countries and high-income countries, we have computed the skill-setting and migration-setting curves of these three 
groups. Results are depicted on Fig. 5. The case for indeterminacy appears to be irrelevant for larger developing and high-income countries. The bad equilibrium B almost coincides with the corner solution A, and the distance between this corner solution and the good equilibrium $\mathrm{C}$ is very large. On the contrary, the bad equilibrium B is clearly different from the corner solution and distance between equilibria $\mathrm{B}$ and $\mathrm{C}$ is much smaller in the case of SIDS. The average picture shows a brain drain of 60 percent in the good equilibrium, and a brain drain of 90 percent in the bad equilibrium. This is clearly driven by the major differences in the distribution of migration costs.

Figure 5. Skill-setting and migration-setting curves by country group
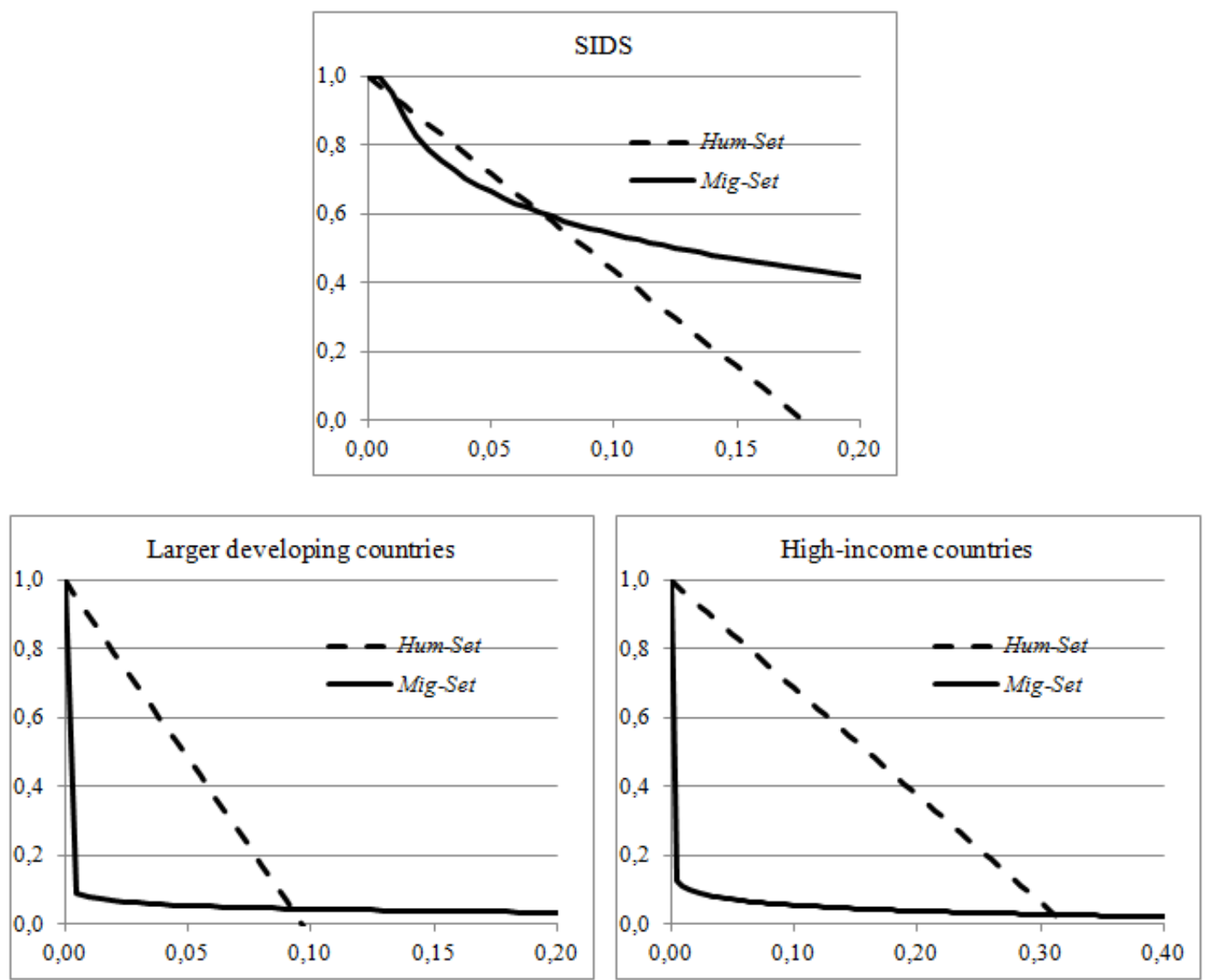
Table 3. Calibration of country-specific parameters

\begin{tabular}{|c|c|c|c|}
\hline Country & $\mathrm{w}(\$ 1,000)$ & $\mathrm{A}$ & $\mathrm{C}$ \\
\hline Antigua \& Barbuda & 21.210 & 105.121 & 2.264 \\
\hline Belize & 13.681 & 87.986 & 3.036 \\
\hline Cape Verde & 10.725 & 96.264 & 5.071 \\
\hline Comoros & 3.384 & 66.832 & 19.012 \\
\hline Cuba & 12.083 & 62.811 & 7.346 \\
\hline Dominica & 16.514 & 68.462 & 2.817 \\
\hline Dominican Republic & 13.381 & 55.473 & 8.979 \\
\hline East Timor & 1.784 & 25.954 & 18.381 \\
\hline Fiji & 10.645 & 83.229 & 3.570 \\
\hline Grenada & 12.788 & 83.422 & 2.441 \\
\hline Guinea-Bissau & 1.440 & 58.009 & 15.305 \\
\hline Guyana & 8.810 & 112.994 & 2.722 \\
\hline Haiti & 4.851 & 154.916 & 3.785 \\
\hline Jamaica & 10.793 & 134.667 & 2.629 \\
\hline Kiribati & 3.453 & 100.034 & 6.037 \\
\hline Maldives & 9.376 & 48.716 & 21.513 \\
\hline Marshall Islands & 6.774 & 52.692 & 6.293 \\
\hline Mauritius & 33.297 & 218.356 & 3.853 \\
\hline Micronesia. Fed States & 8.408 & 66.062 & 6.926 \\
\hline Nauru & 2.892 & 54.198 & 6.181 \\
\hline Palau & 21.464 & 138.432 & 2.813 \\
\hline Papua New Guinea & 10.692 & 172.501 & 14.129 \\
\hline Saint Lucia & 15.748 & 180.617 & 2.694 \\
\hline St Vincent \& Gren. & 16.927 & 164.675 & 2.169 \\
\hline Samoa & 6.948 & 54.029 & 3.634 \\
\hline Sao Tome \& Principe & 3.133 & 50.385 & 12.995 \\
\hline Seychelles & 21.932 & 94.767 & 3.792 \\
\hline Solomon Islands & 5.103 & 148.056 & 11.575 \\
\hline Suriname & 12.380 & 83.312 & 3.176 \\
\hline Tonga & 7.606 & 59.708 & 3.409 \\
\hline Tuvalu & 3.641 & 81.913 & 5.757 \\
\hline Vanuatu & 6.803 & 53.039 & 5.653 \\
\hline SIDS & 10.583 & 94.301 & 6.874 \\
\hline Larger developing states & 8.604 & 74.954 & 48.578 \\
\hline High-income countries & 42.592 & 136.065 & 24.013 \\
\hline
\end{tabular}

Source: Authors' own calculations. 


\subsection{Country-specific results and robustness to the CDF specification}

Let us now analyze the type of equilibrium observed in each country. We have used data on the observed brain drain, human capital and GDP per capita levels to infer country-specific exogenous characteristics and estimate general parameters. Given these parameters, our theory predicts that there is another possible equilibrium, with higher or lower brain drain, and allows us to identify the precise situation of each country (good or bad equilibrium). Which equilibrium is observed, either good or bad, is an outcome of the model. Tab. 4 presents the results. For each SIDS, the left panel gives equilibrium values for $\left(h_{B}, m_{B}\right)$ and $\left(h_{C}, m_{C}\right)$, and the type of equilibrium observed ( $\operatorname{good}=\mathrm{C}$, bad $=\mathrm{B}$ ) under the uniform distribution. In 17 cases, the good equilibrium is observed in the data and the bad equilibrium almost corresponds to the corner solution with 100 percent of brain drain. In 10 cases, the good equilibrium is observed in the data but the bad equilibrium is not far; an adverse shock or self-fulfilling adverse expectations could to a worse situation with brain drain rates between 75 and 90 percent. Finally, we identify 5 cases of coordination failures, i.e. situations in which the bad equilibrium is observed in the data: Grenada, Guyana, Haiti, Jamaica and St. Vincent and the Grenadines.

Obviously, uncertainty surrounds our quantitative conclusions. This is mainly because we have use a series of identifying assumptions shaping the form of the migration-setting equation. In particular, the choice of the uniform distribution for migration costs and the calibration of $\alpha$ play a key role. De la Croix and Docquier (2012) used three different distributions (the Gumbel, Normal and Logistic) and two different values for $\alpha(0.28$ and $0.4)$ to identify the cases of coordination failures. The Gumbel distribution is a continuous probability distribution belonging to the family of generalized extreme value distributions. It is traditionally used in migration models where utility includes an iid random component varying between individuals and countries of destination (see Grogger and Hanson, 2010). Results are reported in the right columns of Tab. 4. With the Gumbel, they found 17 and 21 cases for the two values of $\alpha$. With the Normal and Logistics distributions, they found 22 and 17 cases when $\alpha$ equals 0.4 . Our assumption of uniform CDF is very conservative. 
Table 4. Number of coordination failures in SIDS

\begin{tabular}{|c|c|c|c|c|c|c|c|c|c|}
\hline & \multicolumn{5}{|c|}{ Uniform distribution } & \multicolumn{4}{|c|}{ Alternative distributions } \\
\hline & $m_{\mathrm{B}}$ & $h_{\mathrm{B}}$ & $m_{\mathrm{C}}$ & $h_{\mathrm{C}}$ & Type & Gum1 & Gum2 & $\log 2$ & Nor2 \\
\hline Antigua \& Barbuda & 70.8 & 12.5 & 68.5 & 13.5 & Good & $\mathrm{Bad}$ & Bad & Bad & $\mathrm{Bad}$ \\
\hline Belize & 85.9 & 4.0 & 65.5 & 9.8 & Good & $\mathrm{Bad}$ & $\mathrm{Bad}$ & Bad & $\mathrm{Bad}$ \\
\hline Cape Verde & 100.0 & 0.0 & 44.0 & 6.4 & Good & $\mathrm{Bad}$ & Bad & Bad & $\mathrm{Bad}$ \\
\hline Comoros & 100.0 & 0.0 & 17.8 & 2.4 & Good & Good & Good & Good & Good \\
\hline Cuba & 100.0 & 0.0 & 28.8 & 12.7 & Good & Good & Good & Good & Good \\
\hline Dominica & 84.5 & 7.7 & 63.9 & 16.9 & Good & Bad & $\mathrm{Bad}$ & $\mathrm{Bad}$ & $\mathrm{Bad}$ \\
\hline Dominican Republic & 100.0 & 0.0 & 22.4 & 16.9 & Good & Good & Good & Good & Good \\
\hline East Timor & 100.0 & 0.0 & 21.9 & 3.5 & Good & Good & Good & Good & Good \\
\hline Fiji & 89.2 & 2.0 & 62.8 & 7.6 & Good & $\mathrm{Bad}$ & $\mathrm{Bad}$ & $\mathrm{Bad}$ & $\mathrm{Bad}$ \\
\hline Grenada & 84.3 & 9.6 & 53.2 & 28.5 & $\mathrm{Bad}$ & $\mathrm{Bad}$ & $\mathrm{Bad}$ & Bad & $\mathrm{Bad}$ \\
\hline Guinea-Bissau & 100.0 & 0.0 & 27.7 & 1.0 & Good & Good & Good & Good & Good \\
\hline Guyana & 89.2 & 4.1 & 49.0 & 19.5 & $\mathrm{Bad}$ & $\mathrm{Bad}$ & $\mathrm{Bad}$ & $\mathrm{Bad}$ & $\mathrm{Bad}$ \\
\hline Haiti & 79.9 & 1.3 & 77.0 & 1.5 & $\mathrm{Bad}$ & $\mathrm{Bad}$ & $\mathrm{Bad}$ & $\mathrm{Bad}$ & $\mathrm{Bad}$ \\
\hline Jamaica & 84.7 & 4.3 & 57.0 & 12.0 & $\mathrm{Bad}$ & $\mathrm{Bad}$ & $\mathrm{Bad}$ & $\mathrm{Bad}$ & $\mathrm{Bad}$ \\
\hline Kiribati & 100.0 & 0.0 & 55.7 & 1.5 & Good & Good & Good & $\mathrm{Bad}$ & Good \\
\hline Maldives & 100.0 & 0.0 & 11.0 & 12.7 & Good & Good & Good & Good & Good \\
\hline Marshall Islands & 100.0 & 0.0 & 42.8 & 7.7 & Good & Good & Good & Good & Good \\
\hline Mauritius & 100.0 & 0.0 & 28.5 & 9.5 & Good & $\mathrm{Bad}$ & $\mathrm{Bad}$ & $\mathrm{Bad}$ & $\mathrm{Bad}$ \\
\hline Micronesia. Fed States & 100.0 & 0.0 & 35.7 & 7.6 & Good & Good & Bad & Bad & Good \\
\hline Nauru & 100.0 & 0.0 & 57.3 & 2.6 & Good & Good & $\mathrm{Bad}$ & $\mathrm{Bad}$ & Good \\
\hline Palau & 89.0 & 2.5 & 54.7 & 9.7 & Good & $\mathrm{Bad}$ & Bad & Bad & $\mathrm{Bad}$ \\
\hline Papua New Guinea & 100.0 & 0.0 & 15.8 & 3.1 & Good & Good & Good & Good & Good \\
\hline Saint Lucia & 79.0 & 3.0 & 68.6 & 4.7 & Good & $\mathrm{Bad}$ & $\mathrm{Bad}$ & $\mathrm{Bad}$ & $\mathrm{Bad}$ \\
\hline St Vincent \& Gren. & 81.9 & 5.8 & 49.0 & 16.5 & $\mathrm{Bad}$ & $\mathrm{Bad}$ & $\mathrm{Bad}$ & $\mathrm{Bad}$ & $\mathrm{Bad}$ \\
\hline Samoa & 86.0 & 4.0 & 73.4 & 7.7 & Good & Bad & $\mathrm{Bad}$ & $\mathrm{Bad}$ & $\mathrm{Bad}$ \\
\hline Sao Tome \& Principe & 100.0 & 0.0 & 26.7 & 3.1 & Good & Good & $\mathrm{Bad}$ & $\mathrm{Bad}$ & $\mathrm{Bad}$ \\
\hline Seychelles & 97.0 & 1.0 & 40.0 & 16.1 & Good & $\mathrm{Bad}$ & $\mathrm{Bad}$ & $\mathrm{Bad}$ & $\mathrm{Bad}$ \\
\hline Solomon Islands & 100.0 & 0.0 & 25.7 & 1.5 & Good & Good & Good & Good & Good \\
\hline Suriname & 87.0 & 3.5 & 65.8 & 9.2 & Good & $\mathrm{Bad}$ & $\mathrm{Bad}$ & $\mathrm{Bad}$ & $\mathrm{Bad}$ \\
\hline Tonga & 82.4 & 5.5 & 75.6 & 7.6 & Good & $\mathrm{Bad}$ & $\mathrm{Bad}$ & $\mathrm{Bad}$ & $\mathrm{Bad}$ \\
\hline Tuvalu & 100.0 & 0.0 & 57.5 & 2.0 & Good & Good & Bad & $\mathrm{Bad}$ & Good \\
\hline Vanuatu & 100.0 & 0.0 & 47.5 & 7.7 & Good & Good & Good & Good & Good \\
\hline Coordination failure & - & - & - & - & 5 & 17 & 21 & 22 & 18 \\
\hline
\end{tabular}

Coordination failures are generating strong welfare losses for SIDC's. Their cost in terms of stayers' income and GDP per capita is large. Given Eq. (3), moving from the bad equilibrium $\mathrm{B}$ to the good equilibrium $\mathrm{C}$ induces a relative gain of: 


$$
\frac{d w}{w}=\left(\frac{h_{C}}{h_{B}}\right)^{\alpha}-1
$$

for each stayer (remember low-skilled wages are proportional to high-skilled wages).

And Eq. (1) implies that GDP per capita equals $y=w \theta(h)$ where $\theta(h) \equiv(\omega+h) /(1+h)$ is

clearly increasing in $h$. It follows that $\frac{d y}{y}>\frac{d w}{w}$. For the five countries suffering from coordination failure under the uniform $\mathrm{CDF}$, moving from $\mathrm{B}$ et $\mathrm{C}$ raises wages by $139 \%$ (Grenada), 248\% (Guyana), 12\% (Haiti), 127\% (Jamaica) and 131\% (St Vincent and Grenadines). It raises GDP per capita by 181\% (Grenada), 309\% (Guyana), 12\% (Haiti), 148\% (Jamaica) and 159\% (St Vincent and Grenadines).

\section{Conclusion}

Stimulating human capital accumulation has usually been considered as an adequate policy for developing countries. However, such policies cannot be effective if countries suffer from a massive brain drain. This is particularly the case for small countries where the average brain drain rate exceeds 50 percent and where emigration decisions are strongly responsive to economic conditions. In this paper we document this phenomenon and then study its economic implications. When endogenous performance and emigration decisions are jointly endogenized, multiplicity of equilibria is likely to be observed. Indeed, when a significant brain drain movement is initiated, it may have damaging effects on the economy and induce other waves of high-skill emigration. On the contrary, when a significant return movement operates, it gives incentives to other waves of emigrants to return home. These vicious circles and virtuous cycles are linked to strategic complementarities in individual migration decisions; a situation of high brain drain and low development can be the outcome of a coordination failure. Provided that mass brain drain is a relatively recent phenomenon and the good equilibrium is stable, the likelihood to observe a coordination failure depends on how people might have deviated from the good equilibrium when adverse historical shocks occurred in the recent past. Our analysis reveals that small states are much more likely to be badly coordinated because the elasticity of migration to economic performance is larger. We identified the cases of coordination failure and show that moving to the good equilibrium could raise wages and GDP per capita by more than 100 percent in the most affected 
countries. These countries require appropriate development policies. Subsidizing temporarily the repatriation of high-skill natives working abroad could lead to major sustainable improvement in these countries.

\section{References}

Alesina A, Devleeschauwer A, Easterly W, Kurlat S, Wacziard R (2003) Fractionalization. Journal of Economic Growth 8(2): 155-194.

Barro RJ, Lee JW (2001) International Data on Educational Attainment: Updates and Implications. Oxford Economic Papers 53(3): 541-63.

Beine M, Docquier F (2008) Measuring Skilled Emigration Rates: The Case of Small States. IZA Discussion Paper n. 3388.

Beine M, Docquier F, Rapoport H (2008) Brain drain and human capital formation in developing countries: winners and losers. Economic Journal 118: 631-652.

Beine M, Docquier F, Schiff M (2008) Brain Drain and its Determinants: A Major Issue for Small States. IZA Discussion Paper n. 3398.

Chiswick BR, Miller PW (1995) The Endogeneity between Language and Earning: An International Analysis. Journal of Labor Economics 13(2): 246-88.

Cohen D, Soto M (2007) Growth and human capital: good data, good results. Journal of Economic Growth 12(1): 51-76.

de la Croix D, Docquier F (2012) Do brain drain and poverty result from coordination failures? Journal of Economic Growth 17(1): 1-26.

Domenech R, De La Fuente A (2006) Human Capital in Growth Regressions: How much difference does data quality make? Journal of the European Economic Association 4(1): 1-36.

Docquier F, Lowell LB, Marfouk A (2009) A gendered assessment of highly skilled emigration. Population and Development Review 35(2): 297-322.

Grogger J, Hanson G (2011) Income maximization and the selection and sorting of international migrants. Journal of Development Economics 95(1): 42-57.

Kaufmann D, Kraay A, Mastruzzi M (2005) Governance matters III: Governance Indicators for 1996-2002. Washington DC: the World Bank. 
Lopez R, Schiff M (1998) Migration and the Skill Composition of the Labor Force: The Impact of Trade Liberalization in LDCs. Canadian Journal of Economics 31(2): 318-36.

Lucas RE (1988) On the mechanics of economic development. Journal of Monetary Economics 22(3): 3-42.

Mayda AM (2010) International Migration: a Panel Data Analysis of the Determinants of Bilateral Flows. Journal of Population Economics 23(4): 1249-1274.

Mayer T, Zignago S (2011) A note on CEPII's distances measures. CEPII Working Paper 2011-25.

Rotte R, Vogler M (2000) Effects of Development on Migration: Theoretical Issues and New Empirical Evidence. Journal of Population Economics 13(3): 485-508. 
Institut de Recherches Économiques et Sociales

Université catholique de Louvain

Place Montesquieu, 3

1348 Louvain-la-Neuve, Belgique 